City University of New York (CUNY)

CUNY Academic Works

\title{
Social Media Use and HIV Transmission Risk Behavior Among Ethnically Diverse HIV-Positive Gay Men: Results of an Online Study in Three U.S. States
}

Sabina Hirshfield

Public Health Solutions

Christian Grov CUNY Brooklyn College, CUNY Graduate Center, Center for HIV/AIDS Educational Studies and Training (CHEST)

Jeffrey T. Parsons

CUNY Hunter College

Ian Anderson

Smart + Strong

Mary Ann Chiasson

Public Health Solutions

\section{How does access to this work benefit you? Let us know!}

More information about this work at: https://academicworks.cuny.edu/sph_pubs/148

Discover additional works at: https://academicworks.cuny.edu

This work is made publicly available by the City University of New York (CUNY).

Contact: AcademicWorks@cuny.edu 


\title{
Social Media Use and HIV Transmission Risk Behavior Among Ethnically Diverse HIV-Positive Gay Men: Results of an Online Study in Three U.S. States
}

\author{
Sabina Hirshfield • Christian Grov • Jeffrey T. Parsons • \\ Ian Anderson • Mary Ann Chiasson
}

Received: 11 June 2014 / Revised: 16 February 2015 / Accepted: 21 February 2015

(C) Springer Science+Business Media New York 2015

\begin{abstract}
Though Black and Hispanic men who have sex with men (MSM) are at an increased risk for HIV, few HIV risk reduction interventions that target HIV-positive MSM, and even fewer that use technology, have been designed to target these groups. Despite similar rates of social media and technology use across racial/ethnic groups, online engagement of minority MSM for HIV prevention efforts is low. Since minority MSM tend to have less representation in online HIV prevention studies, the goals of this online anonymous study of HIV-positive gay-identified men were to test the feasibility of conducting targeted recruitment by race/ethnicity and sexual orientation, to assess technology and social media use, and to assess global HIV transmission risk. In 2011, an anonymous online survey was conducted among 463 members of an HIV-positive personals website. Emails were sent to a subset of HIV-positive male members who self-identified as gay. While $57 \%$ were White, substantial proportions of participants were Black $(20 \%)$ or Hispanic $(18 \%)$.
\end{abstract}

\author{
S. Hirshfield $(\varangle) \cdot$ M. A. Chiasson \\ Research and Evaluation Unit, Public Health Solutions, 40 Worth Street, \\ 5th Floor, New York, NY 10013, USA \\ e-mail: shirshfield@healthsolutions.org \\ C. Grov $\cdot$ J. T. Parsons \\ Center for HIV/AIDS Educational Studies and Training (CHEST), \\ New York, NY, USA \\ C. Grov \\ Health and Nutrition Sciences, Brooklyn College, Brooklyn, NY, USA \\ C. Grov $\cdot$ J. T. Parsons \\ The Graduate Center of the City University of New York (CUNY), \\ New York, NY, USA \\ J. T. Parsons \\ Department of Psychology, Hunter College, New York, NY, USA \\ I. Anderson \\ Smart + Strong, New York, NY, USA
}

Median age was 46 (range 18-79). Men who reported using 3 or more websites or apps to meet sex partners were significantly more likely to report anal intercourse (AOR 4.43, $p<.001$ ) and condomless anal sex (CAS) (AOR 2.70, $p<.05)$ in the past 3 months. The only predictor of CAS with HIV-negative or unknown status partners was being under age 30 (AOR 3.38, $p<$ $.01)$. This study helped to inform online targeted recruitment techniques, access to technology and social media use, and sexual risk among a diverse sample of HIV-positive gay men. Efficacy trials of technology-based HIV prevention interventions targeting high-risk minority HIV-positive MSM are warranted.

Keywords HIV-positive - Social media - Technology · Gay $\cdot$ Sexual orientation

\section{Introduction}

Though Black and Hispanic gay men and other men who have sex with men (MSM) are at an increased risk for HIV, few HIV risk reduction interventions that target HIV-positive MSM, and even fewer that use technology, have been designed to target these groups (Sullivan et al., 2011). Despite similar rates of usage of technology and social media across racial/ethnic groups, online engagement of minority MSM for HIV prevention efforts is low (Chiasson, Shaw, Humberstone, Hirshfield, \& Hartel, 2009; Fernandez et al., 2007; Rosser et al., 2009). There are two likely explanations for the disparity in engagement with online HIV prevention studies for minority MSM. First, it is estimated that minority men constitute only $13 \%$ of the U.S. male population (U.S. Census Bureau, 2012), which may account for the smaller proportion of minority respondents who complete online surveys. Second, online recruitment bias may occur. Sullivan et al. (2011) reported on under-enrollment of U.S. minority MSM in online HIV prevention studies, where rates of under-enrollment ranged from 29-84 \% for Black MSM 
and 6-89\% for Hispanic MSM. High under-enrollment may have been due to differential click-through rates on banner ads that under-represented minority MSM, or not recruiting men from sites that cater to minority MSM (e.g., Black Gay Chat).

MSM are known for being early adopters of technology and social media (Bolding, Davis, Sherr, Hart, \& Elford, 2004; Wong, Gullo, \& Stafford, 2004). Social media has been defined as mobile and web-based technologies that enable individuals and (online) communities to share, co-create, social network, and modify usergenerated content, which includes words, pictures, videos and audio (Curtis, 2013; Kietzmann, Hermkens, McCarthy, \& Silvestre, 2011). Social media interventions for MSM at high risk of HIV have been successfully implemented through videos, interactive games, mobile applications (apps), online communities, and text messaging (Grov, Breslow, Newcomb, Rosenberger, \& Bauermeister, 2014; Mustanski, Garofalo, Monahan, Gratzer, \& Andrews, 2013). The U.S. population online now has similar proportions of White, Black, and Hispanic adults (Pew Research Center, 2011; Smith, 2010b), with Blacks and Hispanics being more likely to own a mobile phone and use it for text messaging and social media than Whites (Smith, 2010a). A recent study of MSM in New York City found that $72 \%$ owned a smartphone and an additional $8 \%$ said they planned to buy one within the year (Grov, Ventuneac, Rendina, Jimenez, \& Parsons, 2013).

Recent technology-based interventions for HIV-positive populations have focused on disease prevention and healthcare, such as medication adherence, rather than reducing sexual risk, and have been delivered via texting and on computers (Gamage et al., 2011; Harris et al., 2010; Horvath et al., 2013; Pellowski \& Kalichman, 2012). As many HIV-positive MSM use social media and sexual networking sites to meet sex partners (Grov, Golub, \& Parsons, 2010; Liau, Millett, \& Marks, 2006), these venues may also be effective places to engage men in prevention and intervention efforts when and where they choose, as opposed to requiring a structured clinical or research setting (Hooper, Rosser, Horvath, Oakes, \& Danilenko, 2008; Wolitski, Gomez, \& Parsons, 2005).

The goals of this study were to test the feasibility of conducting targeted online recruitment by race/ethnicity and sexual orientation, to assess technology and social media use, and to assess current global HIV transmission risk among an online sample of HIVpositive men from the U.S. The personals section of POZ.com (POZ Personals), a website for HIV-positive individuals, was the recruitment source for this study.

\section{Method}

Participants

This study represented a collaboration between the research team and POZ, a U.S.-based website which describes itself as serving the community of people living with, and those affected by, HIV/ AIDS since 1994. POZ.com provides health information about HIV, sexually transmitted infections (STIs), and other chronic health conditions such as Hepatitis C. POZ.com also provides a national health services directory, covers HIV-related local and international news, as well as blogs, forums, and a personals section for HIV-positive individuals, which currently has over 150,000 U.S. members.

During the 7-day recruitment period, November 28 to December 5, 2011, POZ Personals sent an internal system message to a subset of HIV-positive male members who were at least 18 years of age, self-identified as gay, and had logged into the website at least once in the past 6 months $(n=5,260)$. During the recruitment period, POZ implemented three recruitment steps. First, messages were sent to members in New York and California, regardless of race or ethnicity. These two states were selected for online recruitment based on their population size and POZ Personals member base. Next, messages were sent to members in Georgia, targeting nonBlack-identified men (to ensure a sample of men identifying as White and other race or ethnicity). Finally, messages were sent to Georgia members who identified as Black. Georgia was selected to test the feasibility of targeted recruitment by race/ethnicity, as it had a high proportion of Black-identified members. All email recipients were considered potentially eligible.

The research team and POZ staff worked together to develop messaging for the study recruitment email. The study email subject line was "Time to take a quick survey about technology and sex?" and the body of the email contained the following message: "POZ has teamed up with Public Health Solutions to create a survey asking about what kinds of technology you use and about your recent sexual behavior. It will only take a few minutes and it will help POZ Personals develop future enhancements and Public Health Solutions to continue their mission of 'generating practical solutions to major public health challenges.' If you're interested, please click on the link to read the consent form and answer the short survey." An embedded link was provided within the email; clicking on the link led potential participants to a secure webbased consent form and anonymous survey. Men provided consent by reading the consent form and clicking a button at the bottom of the form to agree to participate in the anonymous survey. The survey was provided in English and took less than $5 \mathrm{~min}$ to complete. Demographic characteristics, technology use, and sexual behavior in the past 3 months were assessed. Following completion of the online survey, all participants were provided an exit page containing web links to HIV/STI, drug, alcohol, and mental health treatment. The survey was optimized to allow for survey completion on smartphones and tablets. No incentives were offered to study participants. The institutional review board at Public Health Solutions approved all study procedures. POZ. com provided data for age, race/ethnicity, and education from its current (2014) POZ Personals member base to enable us to make comparisons with the study sample. 


\section{Measures}

The survey assessed demographic characteristics (i.e., age, sexual orientation, ethnicity and race, and education), technology (i.e., ownership of a laptop or netbook, a smartphone [like an iPhone or Blackberry], tablet computer like an iPad, or a basic cell phone [i.e., without Internet access or apps]), and social media use on a laptop, smartphone, or tablet (e.g., Facebook/Twitter, online banking, downloading apps, listening to music, reading books or the news, using email, watching videos, playing games, posting photos, making a video, sending or receiving texts, taking pictures, sending pictures, or talking on the phone). In terms of meeting sex partners, we asked the question, "What online sites do you use to meet men? [check all that apply]". Participants were presented a list of 12 common social and sexual websites or apps, as well as the ability to type in additional sites they used. Men could also indicate they did not use online sites or apps to meet sex partners.

Global sexual risk questions inquired about recent behaviors: "In the past 90 days, how many men have you had anal sex with?" "How many men did you have anal sex without a condom?" (All, some, none, not sure, refuse). "With the men that you had anal sex without a condom, how many were HIV-positive?"(All, some, none, not sure, refuse). Condomless anal sex (CAS) was defined as insertive or receptive anal intercourse without a condom. Serodiscordant, or potentially discordant, CAS was defined as any condomless anal sex with a partner of negative or unknown HIV status (Rosser et al., 2010a). We did not inquire about viral suppression.

\section{Statistical Analysis}

Data analyses were performed using IBM SPSS version 20 (IBM, 2012). Bivariate associations significant at $p<.05$ were included in multivariable logistic regression models. In a logistic regression with anal sex $(y / n)$ as the dependent variable, the Rao score test for smartphone or tablet activities indicated that the four highest scores at $p<.001$ were sending or receiving text messages (13.22), using Facebook or Twitter (12.83), downloading apps (12.68), and sending photos on your cellphone (10.74). The apps and photos variables were moderately correlated with the Facebook/Twitter $(0.50$ and 0.45 , both $p<.01)$ and texting variables $(0.37$ and 0.43 , both $p<.01$ ); as social networking and texting were conceptually relevant to the analysis, the apps and photo variables were excluded. Survey outcome rates and methodological terminology are based on the reporting standards of the American Association for Public Opinion Research (AAPOR, 2011).

\section{Results}

Targeted Recruitment

Of the 5,260 men emailed, 1,696 (32\%) clicked on the study hyperlink taking them to the landing page and informed consent document. Of these men, $28 \%(479 / 1,696)$ consented to participate. For recruitment in Georgia, we tested the feasibility of targeting participants by race/ethnicity and compared response rates of non-Black-identified and Black-identified participants. The response rate did not differ significantly for these two groups (14\% vs. $9 \%, p=.075)$. The POZ Personals member emails contained a unique session ID code; 2 incomplete cases were identified as duplicates (and excluded) during data cleaning. Among men who consented, 463 (97\%) completed the survey. Most men completed the survey on a personal computer $(64 \%)$, followed by a Macintosh $(28 \%)$, and cellphone or tablet ( $8 \%)$; no demographic differences were seen by the type of device used to take the survey. Table 1 describes the demographic characteristics of the sample and compares the study sample (from 2011) to the POZ Personals member base (from 2014) by age, race/ethnicity and education. Mean age of the study sample (46, range 18-79, SD 10.17) was significantly higher $(p<.001)$ than the estimated mean age of the POZ Personals member base (44, range 18-94, SD 12.67). Specifically, a higher proportion of men recruited for the study were $40-49\left(\chi^{2}[3]=13.44, p<.001\right)$ and 50 and over $\left(\chi^{2}[3]=7.29\right.$, $p<.01)$. Compared to the POZ Personals member base, the study sample had significantly more Black $\left(20 \%, \chi^{2}[3]=35.25, p<\right.$ $.001)$ and Hispanic $\left(18 \%, \chi^{2}[3]=36.07, p<.001\right)$ HIV-positive men, indicating that targeted recruitment by race/ethnicity was successful. About half of the study sample had a college degree or more, which was similar to the POZ Personals member base. As respondents were targeted by their self-reported sexual identity (gay) on the personals site, almost all respondents identified as gay, homosexual or same-gender loving.

\section{Technology Use}

Most men owned a laptop or netbook, followed by a smartphone, tablet or basic cell phone. In total $85 \%$ of participants owned a cell phone with $65 \%$ of these men reporting a smartphone, $16 \%$ a basic cell phone, and $4 \%$ reporting both phone types. Men reported using their cell phone or tablet for a range of activities, from playing games and watching videos to downloading apps to texting and emailing (Table 1). In addition, $70 \%$ reported owning multiple technological devices (i.e., a laptop, smartphone and/or a tablet), and a multivariable logistic regression found that owning multiple devices was associated with being younger than 50 (18-29 AOR 3.13, $95 \%$ CI 1.33, 7.36; 30-39 AOR 4.91, $95 \%$ CI 2.45, 9.83; 40-49 AOR 2.35, $95 \%$ CI 1.46, 3.77) and having a college degree or more (AOR 1.69, $95 \%$ CI 1.11, 2.60), though no difference was seen by race/ethnicity.

To determine whether there were demographic differences by social media use, we conducted a series of multivariable analyses by age, race/ethnicity and education (Table 2). Compared to men age 50 and over, younger men were significantly more likely to own a smartphone and had significantly higher odds of using their smartphone or tablet for Facebook or Twitter, downloading an app, playing a game or listening to music, posting or sending 
Table 1 Characteristics of gay-identified HIV-positive study sample and host website, POZ Personals: results from an online study in three U.S. states, 2011

\begin{tabular}{|c|c|c|c|}
\hline Characteristic & $\begin{array}{l}\text { Study } \\
N(\%)\end{array}$ & $\begin{array}{l}\mathrm{POZ} \\
\text { Personals } \\
N \%\end{array}$ & $p$ value \\
\hline Age & $N=463$ & $N=99,758$ & \\
\hline $18-29$ & $37(8)$ & $12,218(12)$ & \\
\hline $30-39$ & $85(18)$ & $23,955(24)$ & \\
\hline $40-49$ & $181(39)$ & $31,170(31)$ & \\
\hline $50+$ & $160(35)$ & $32,415(33)$ & $<.0001$ \\
\hline Race/ethnicity & $N=463$ & $N=75,276$ & \\
\hline White & $266(57)$ & $46,526(62)$ & \\
\hline Black & $92(20)$ & $10,340(14)$ & \\
\hline Hispanic & $82(18)$ & $8,968(12)$ & \\
\hline Other race & $23(5)$ & $9,442(12)$ & $<.0001$ \\
\hline Education & $N=463$ & $N=67,077$ & \\
\hline Less than college & $212(46)$ & $33,013(49)$ & \\
\hline College degree or more & $251(54)$ & $34,064(51)$ & 0.154 \\
\hline \multicolumn{4}{|l|}{ Sexual orientation } \\
\hline Gay/homosexual/same-gender loving & $447(96)$ & & \\
\hline Bisexual: I have sex with men and women & $6(1)$ & & \\
\hline Queer: I have sex with men & $9(2)$ & & \\
\hline Other: I have sex with men & $1(<1)$ & & \\
\hline \multicolumn{4}{|l|}{ Websites or apps to meet men } \\
\hline 0 & $34(7)$ & & \\
\hline 1 & $61(13)$ & & \\
\hline 2 & $115(25)$ & & \\
\hline 3 or more & $253(55)$ & & \\
\hline \multicolumn{4}{|l|}{ Owns $\mathrm{a}^{\mathrm{a}}$} \\
\hline Laptop or netbook & $380(82)$ & & \\
\hline Tablet & $93(20)$ & & \\
\hline Smartphone & $319(69)$ & & \\
\hline Feature phone & $93(20)$ & & \\
\hline Unlimited data plan & $318(69)$ & & \\
\hline \multicolumn{4}{|l|}{ Uses cellphone or tablet to ${ }^{a}$} \\
\hline Use Facebook or Twitter & $267(58)$ & & \\
\hline Download an app & $271(58)$ & & \\
\hline Play a game & $195(42)$ & & \\
\hline Play music & $260(56)$ & & \\
\hline Post a photo or video online & $226(49)$ & & \\
\hline Send a photo or video to someone & $296(64)$ & & \\
\hline Send or receive email & $345(75)$ & & \\
\hline Send or receive text messages & $381(82)$ & & \\
\hline Watch a video (YouTube, Podcast) & $251(54)$ & & \\
\hline
\end{tabular}

${ }^{a}$ Categories are not mutually exclusive. Some variables have missing data. Chi square goodness-of-fit statistic used. Study data collected in 2011; POZ Personals data provided in 2014

photos or videos, emailing, texting, or watching videos. Compared to White men, men of mixed or other race had significantly lower odds of using Facebook or Twitter or posting a photo or

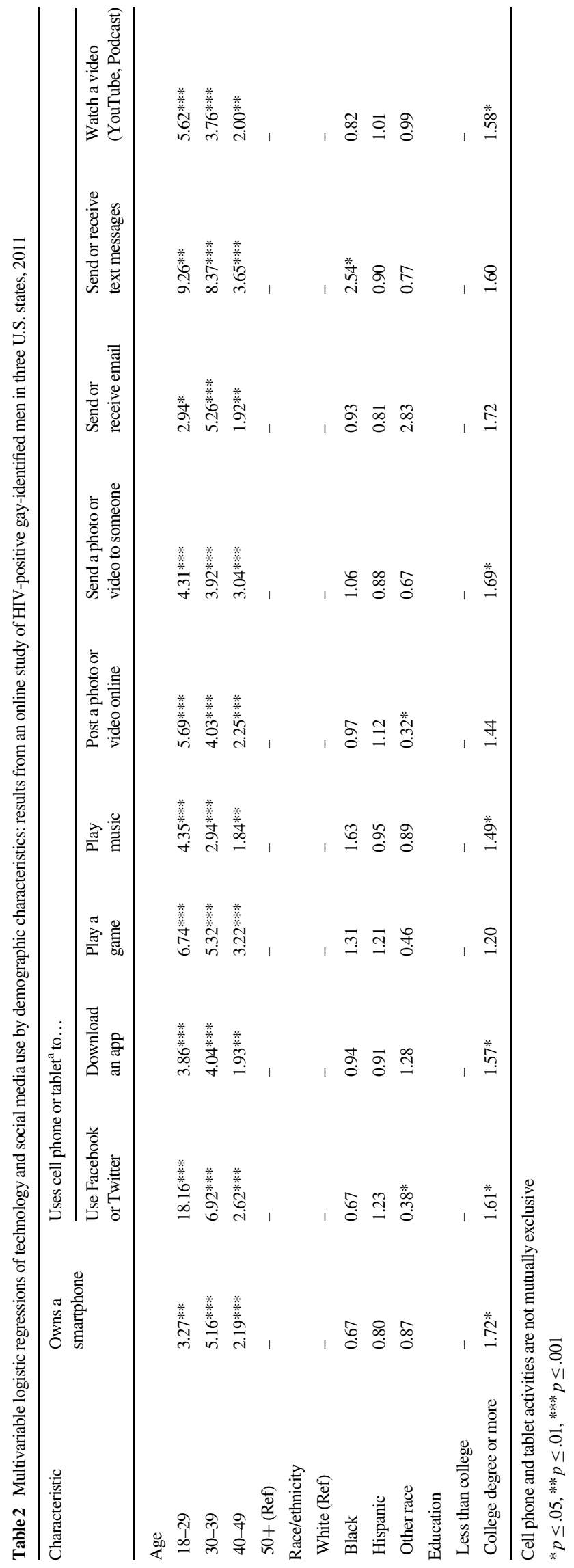


video online, while Black men had significantly higher odds of using their phone for sending or receiving text messages. Finally, compared to men with less than a college degree, men with a college degree or more had significantly higher odds of owning a smartphone and using it (or a tablet) for Facebook or Twitter, downloading apps, playing music, sending photos and videos to others, and watching videos.

\section{Sexual Risk}

In the past 3 months, $78 \%$ reported anal sex with men (median number of partners $=3$ ), $61 \%$ reported CAS, and $39 \%$ reported CAS with HIV-negative or unknown status men, with no differences by race/ethnicity or education (Table 3 ). Respondents were asked about the types of websites or apps that they used to meet male sex partners. Aside from social networking websites such as Facebook and Twitter, the majority of sites were for sexual networking. The most prevalent websites or apps that men reported for meeting men were Adam4Adam (57\%), Craigslist (27\%), Manhunt (26\%), and the sexual networking app, Grindr (23\%). Compared to White men, Black men were significantly more likely to report meeting men on Adam4Adam (OR 2.51, $95 \%$ CI 1.49, 4.24) but were significantly less likely to report meeting men on Manhunt (OR 0.37, $95 \%$ CI 0.19, 0.71). No other racial or ethnic differences were found by type of website. In Table 3, men younger than age 50 were significantly more likely to report past 3-month anal sex with male partners, though no difference was seen by race/ethnicity or education. Compared with men who had not used an app or website to meet men for sex, respondents who reported 2 websites/apps or 3 or more websites/apps were significantly more likely to report male anal sex partners in the past 3 months. Compared with men who did not report owning a laptop, netbook or smartphone, men who owned these devices were significantly more likely to report having anal sex with men in the past 3 months. Men who accessed Facebook or Twitter, or sent or received text messages were also significantly more likely to engage in anal sex in the past 3 months. In multivariable logistic regression (Table 4), men aged 30-39 were significantly more likely to report past 3 -month anal sex compared with men aged 50 and over (AOR 2.74); compared with men not using websites/apps to meet sex partners, men who used 2 websites/apps (AOR 2.39) or 3 or more websites/apps (AOR 4.43) to meet male sex partners were significantly more likely to report past 3-month anal sex.

Compared with men age 50 and over, men between the ages of 30 and 49 were significantly more likely to report past 3-month CAS (Table 3). No differences in CAS were found by race/ethnicity or education. Men who reported using 3 or more websites/ apps to meet male sex partners were significantly more likely than men not using these venues to report past 3-month CAS. Owning a laptop, netbook, tablet or smartphone was significantly associated with engaging in CAS with men in the past 3 months. Men reporting
Facebook or Twitter use or sending and receiving text messages had significantly greater odds of reporting past 3-month CAS than men not reporting these social media activities. In multivariable analysis (Table 4), predictors of past 3-month CAS included meeting men on 3 or more websites/apps (AOR 2.70), and owning a laptop or netbook (AOR 1.79). Fewer characteristics were associated with reporting CAS with serodiscordant/unknown status partners in the past 3 months. The bivariate predictor of reporting CAS with serodiscordant/unknown status partners in the past 3 months was being younger than age 40 (Table 3 ). In multivariable analysis, the only predictor of CAS with serodiscordant/unknown status partners was being under age 30 (AOR 3.38) (Table 4).

\section{Discussion}

In this study, a diverse sample of HIV-positive gay men was recruited on POZ Personals through targeted emails by race/ethnicity, self-reported sexual orientation, and U.S. state. As a result, $43 \%$ were non-White, which is higher than prior online studies not using targeted recruitment approaches (Hirshfield et al., 2012; Navejas, Neaigus, Torian, \& Murrill, 2012; Rosser et al., 2010b). Having access to an online member base, with the ability to program recruitment parameters, particularly for race/ethnicity, enabled us to reach more Black gay men. This approach provided individuals a greater opportunity to enroll, and we found similar response rates for Black- and non-Black-identified participants. As the Black U.S. male population is much smaller than the White U.S. male population, targeting recruitment by race/ethnicity is a useful tool for obtaining a comparable sample size.

For online HIV prevention research that utilizes banner ads, Sullivan et al. (2011) suggested that mirroring the racial/ethnic composition of banner advertisements to a specific target population may mitigate the lower click-through rates of racial and ethnic minority men. Regardless of recruitment methodology, there will always be individuals who do not elect to participate in online or mail-in surveys, and in-person or phone interviews.

The finding that older men tended to take the survey, compared to the POZ Personals member base, suggests that future recruitment of HIV-positive MSM should include age as a target criterion in order to increase participation and representation of younger HIV-positive MSM. Our findings demonstrate the importance of engaging HIVpositive minority and non-minority gay men in prevention efforts. Men who used social media on smartphones or tablets for social and sexual networking were significantly more likely to report recent sexual activity than their non-social media using counterparts. Findings from reported technology use suggest that it is not just the type of device being used, but how it is used, and where this population can be reached and engaged for HIV prevention efforts. For HIV-positive Black MSM and those under age 30, social media, texting, games, videos and apps may be effective ways to reach men with HIV prevention content. 
Table 3 Bivariate analyses of HIV-positive gay men reporting past 3-month sexual behaviors: results from an online study in three U.S. states, 2011

\begin{tabular}{|c|c|c|c|c|c|c|c|c|c|}
\hline \multirow[t]{2}{*}{ Characteristic } & \multicolumn{3}{|l|}{ Anal Sex } & \multicolumn{3}{|l|}{ CAS } & \multicolumn{3}{|c|}{ Serodiscordant CAS } \\
\hline & $\begin{array}{l}\text { Yes } \\
n(\%)\end{array}$ & $\begin{array}{l}\text { No } \\
n(\%)\end{array}$ & $p$ & $\begin{array}{l}\text { Yes } \\
n(\%)\end{array}$ & $\begin{array}{l}\text { No } \\
n(\%)\end{array}$ & $p$ & $\begin{array}{l}\text { Yes } \\
n(\%)\end{array}$ & $\begin{array}{l}\text { No } \\
n(\%)\end{array}$ & $p$ \\
\hline \multicolumn{10}{|l|}{ Age } \\
\hline $18-29$ & $34(9)$ & $3(3)$ & .008 & $23(8)$ & $13(7)$ & .206 & $22(12)$ & $11(4)$ & .001 \\
\hline $30-39$ & $77(21)$ & $8(8)$ & .000 & $61(22)$ & $22(13)$ & .002 & $39(22)$ & $43(17)$ & .034 \\
\hline $40-49$ & $143(40)$ & $38(38)$ & .023 & $116(41)$ & $63(36)$ & .019 & $69(38)$ & $104(40)$ & .224 \\
\hline $50+(\operatorname{Ref})$ & $109(30)$ & $51(51)$ & & $83(29)$ & $76(44)$ & & $50(28)$ & $100(39)$ & \\
\hline \multicolumn{10}{|l|}{ Race/ethnicity } \\
\hline White (Ref) & $204(56)$ & $62(62)$ & & $164(58)$ & $99(57)$ & & $95(53)$ & $157(61)$ & \\
\hline Black & $71(20)$ & $21(21)$ & .925 & $58(21)$ & $33(19)$ & .815 & $40(22)$ & $49(19)$ & .230 \\
\hline Hispanic & $70(19)$ & $12(12)$ & .096 & $49(17)$ & $32(18)$ & .763 & $35(19)$ & $41(16)$ & .193 \\
\hline Other race & $18(5)$ & $5(5)$ & .864 & $12(4)$ & $10(6)$ & .470 & $10(6)$ & $11(4)$ & .372 \\
\hline \multicolumn{10}{|l|}{ Education } \\
\hline Less than college (Ref) & $166(46)$ & $46(46)$ & & $131(46)$ & $77(44)$ & & $90(50)$ & $113(44)$ & \\
\hline College degree or more & $197(54)$ & $54(54)$ & .962 & $152(54)$ & $97(56)$ & 671 & $90(50)$ & $145(56)$ & .200 \\
\hline \multicolumn{10}{|c|}{ Websites or apps to meet men } \\
\hline 0 (Ref) & $18(5)$ & $16(16)$ & & $14(5)$ & $19(11)$ & & $11(6)$ & $22(9)$ & \\
\hline 1 & $36(10)$ & $25(25)$ & .567 & $28(10)$ & $33(19)$ & .746 & $17(10)$ & $41(16)$ & .690 \\
\hline 2 & $89(24)$ & $26(26)$ & .007 & $61(22)$ & $53(30)$ & .264 & $40(22)$ & $66(26)$ & .647 \\
\hline 3 or more & $220(61)$ & $33(33)$ & .000 & $180(63)$ & $69(40)$ & .001 & $112(62)$ & $129(50)$ & .158 \\
\hline \multicolumn{10}{|l|}{ Owns $\mathrm{a}^{\mathrm{a}}$} \\
\hline Laptop or netbook & $310(85)$ & $70(70)$ & .000 & $244(86)$ & $131(75)$ & .003 & $150(83)$ & $209(81)$ & .533 \\
\hline Tablet & $77(21)$ & $16(16)$ & .249 & $69(24)$ & $24(14)$ & .006 & $40(22)$ & $51(20)$ & .533 \\
\hline Smartphone & $262(72)$ & $57(57)$ & .004 & $209(74)$ & $105(60)$ & .002 & $131(73)$ & $170(66)$ & .126 \\
\hline Feature phone & $69(19)$ & $24(24)$ & .270 & $55(19)$ & $37(21)$ & .636 & $28(16)$ & $59(23)$ & .059 \\
\hline Unlimited data plan & $262(72)$ & $56(56)$ & .002 & $206(73)$ & $109(63)$ & .023 & $126(70)$ & $176(68)$ & .692 \\
\hline \multicolumn{10}{|c|}{ Uses cellphone or tablet for ${ }^{\mathrm{a}}$} \\
\hline Facebook or Twitter & $225(62)$ & $42(42)$ & .000 & $179(63)$ & $85(49)$ & .002 & $112(62)$ & $140(54)$ & .097 \\
\hline Send or receive texts & $311(86)$ & $70(70)$ & .000 & $246(87)$ & $131(75)$ & .001 & $152(84)$ & $209(81)$ & .353 \\
\hline
\end{tabular}

${ }^{a}$ Categories are not mutually exclusive

OR odds ratio, CI confidence interval. Feature phone cell phone with no internet access or apps, CAS anal sex without a condom. Serodiscordant CAS serodiscordant, or potentially discordant, condomless anal sex with HIV-negative or unknown status partners. Significant findings in bold

Online and mobile technology use for meeting sex partners was common among HIV-positive gay men in this study. While slightly more than half of the sample reported using 3 or more websites or apps to meet sex partners, men who did so were significantly more likely to report anal sex (AOR 4.43) and CAS (AOR 2.70). Preventing HIV transmission from HIV-positive gay men can have a potentially great public health impact (Janssen \& Valdiserri, 2004). Many HIV-positive individuals modify their sexual behaviors to reduce possible transmission after receiving an HIV-positive diagnosis (Gorbach, Drumright, Daar, \& Little, 2006); however, a growing number of studies indicate that, while some HIV-positive individuals initially reduce HIV transmission risk during the first 12 months post-diagnosis, a substantial proportion reports increased transmission risk 12-24 months post-diagnosis (Gorbach et al., 2011; Heijman et al., 2012).
The use of antiretroviral treatment to attain viral suppression of HIV greatly reduces the risk of sexual HIV transmission (Cohen et al., 2011). In the current study, we did not inquire about viral suppression; however, based on current literature, it is possible that only about a third of participants under age 30 were virally suppressed (Singh et al., 2014). What is concerning is that, although only $8 \%$ of the study sample was under age 30 , younger HIV-positive men in the current study were significantly more likely than older men to report CAS with HIV-negative or unknown status partners, regardless of race/ethnicity, education, or social media use. It may be that younger HIV-positive gay men have less experience with sexual negotiation with their sex partners than older HIV-positive gay men, or men who have had HIV for a longer time (Semple, Patterson, \& Grant, 2000). Online communities, videos, and interactive games that include sexual nego- 


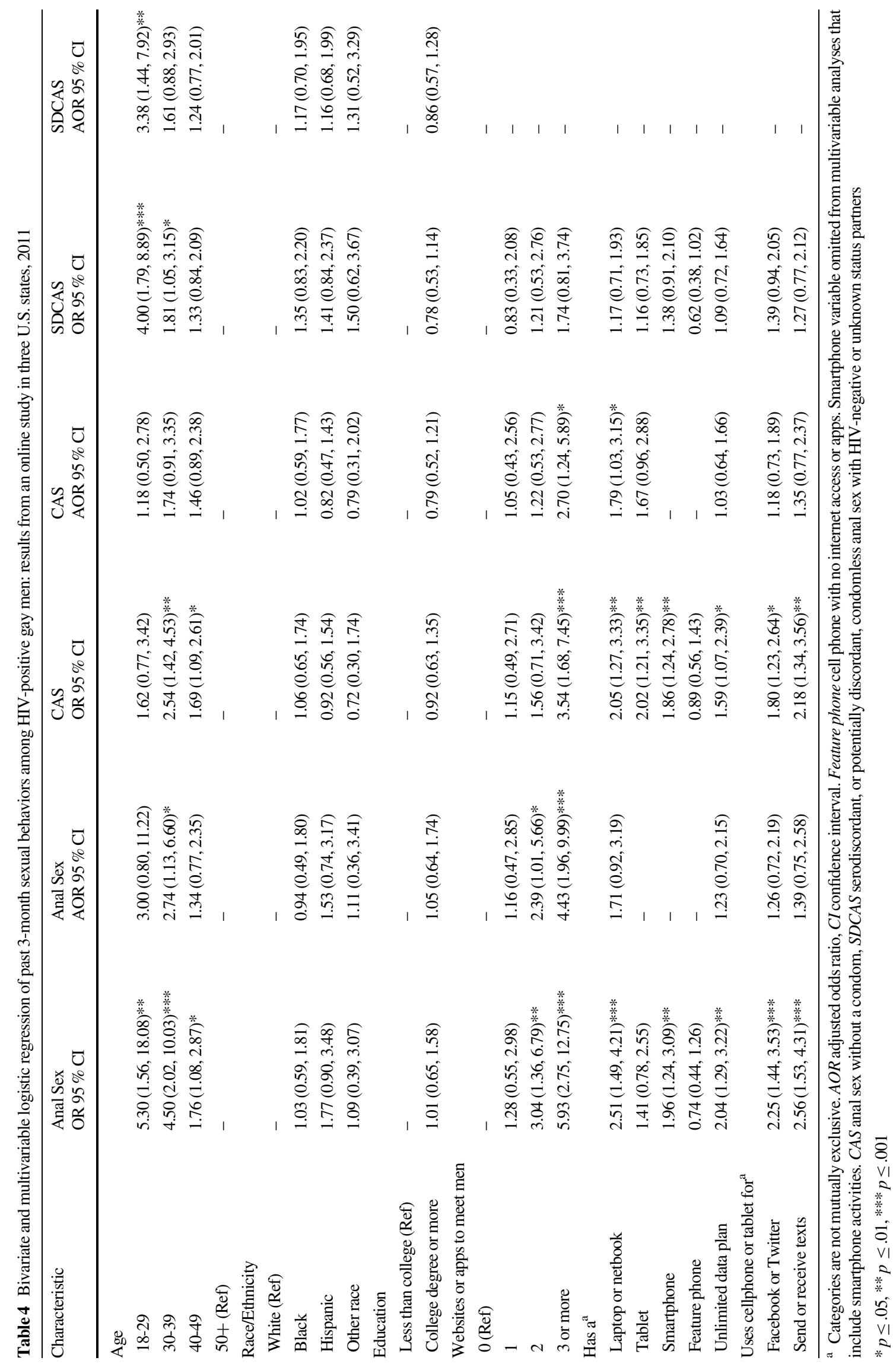


tiation and sexual scripts are critical to educate and model safer sex behaviors (Christensen et al., 2013; Hirshfield et al., 2012; Young, 2013).

Historically, online research has had lower response rates than offline research as there are fewer social constraints compared to in-person interviewing (Birnbaum, 2004). The participation rate (i.e., number of respondents providing usable data divided by the number of initial personal invitations requesting participation) (AAPOR, 2011) was 8.8\% (AAPOR RR 1), which is higher than a large, un-incentivized, online study in the field that used similar recruitment methods (Hirshfield et al., 2012), but comparable to a large online study that did provide incentives (Horvath et al., 2012). The survey in the current study was advertised as brief, and took less than 5 min to complete, which may have contributed to higher response rates. In addition, the $32 \%$ click-through rate in the current study was approximately 10 times higher than a comparable recruitment design conducted on a gay-oriented sexual networking website (Hirshfield et al., 2012). The most likely reason for the differential click-through rate between studies was that the current study email was only sent to active POZ Personals members who frequently check their messages, whereas the other study sent emails to all of their members, regardless of member activity. Finally, the recruitment strategy for this online survey was the utilization of an email list that included members from three U.S. states of a personals website for HIV-positive individuals. For researchers who do not have financial resources to pay for an advertising campaign, alternative free online recruitment methods include gaining permission from local or national listserv administrators of HIV prevention groups to post a study banner, posting an ad on Craigslist Volunteer's section (locally or nationally), and contacting local HIV prevention community based organizations to ask permission to post a study banner on their website.

\section{Limitations}

Our data have limitations that deserve mention. We conducted targeted recruitment by sexual orientation and race/ethnicity but not by age. While the representativeness of younger MSM was slightly lower than the age demographic in the overall POZ Personals sample, it is clear that the age range of study participants does not represent all MSM or current trends in the HIV epidemic (Singh et al., 2014). However, we were able to successfully recruit enough young MSM to maintain statistical power. POZ Personals' online system had the ability to target bisexual men, though we did not target this subgroup, as we reached the desired sample size with gay-identified men; however, bisexual men may have a different technology use and risk profile that warrants further investigation. It is important to note that, although all men were recruited online and had Internet access, there were apparent differences in technology and social media use. It is possible that fewer disparities now exist than when the study was conducted in 2011 since technology has become increasingly more affordable. The current study was not conducted for the purpose of estimating
HIV transmission risk. We utilized global measures, also known as "incidence reports"(Catania et al., 2005), to capture risk behaviors that occurred during the past 90 days. This approach has been used with high HIV prevalence populations (Mustanski, Garofalo, Herrick, \& Donenberg, 2007), where even minimal endorsements of risk during short-time intervals may be more telling than inquiring about a single encounter during the same time frame (Catania et al., 2005). Nevertheless, we did not collect certain indicators that would have provided a fuller profile of global risk behaviors, such as viral suppression or CD4 count, time since HIV diagnosis, number of sexual partners prior to the past 3 months, partner type(s), context of sexual encounters (e.g., oneon-one, group sex), or usual sexual negotiation behaviors (e.g., HIV disclosure, condom use discussion, sexual positioning). Also, we only inquired about male sex partners met online and are therefore unable to determine whether sexual risk may have differed by venue. Further, we did not collect 'click' data for the exit page links to HIV/STI, drug, alcohol, and mental health treatment. Future research in this area should assess the characteristics and needs of participants who click on treatment and prevention exit page links. Finally, the findings from this online study may not be generalizable to all HIV-positive gay men who access personals websites, to HIV-positive MSM who do not identify as gay, to POZ Personals gay members outside of the three U.S. states from which men were recruited, to men who were exposed to the study email but did not click on it, or to men who do not identify as Black, White or Hispanic.

\section{Conclusions}

As new HIV infections in gay and other MSM have been attributed in part to increased access to sex partners via the Internet (Wolitski, 2005), it is critical to deliver behavioral interventions to HIV-positive gay men online to reach many high-risk men at a relatively low cost (Chiasson et al., 2006; Stall \& van Griensven, 2005), engage HIV-positive gay men where they meet sex partners (Rosser et al., 2010b), give men the option to participate on their own time in a private setting, as opposed to a structured clinical setting (Wolitski et al., 2005), and reach ethnically diverse men who may have differential transmission risk and engagement in prevention initiatives. A recent study successfully increased recruitment of minority MSM on a social networking website by targeting banner ads to participants by race/ethnicity (Sullivan et al., 2011). In the current study, conducting targeted recruitment within a known population parameter (e.g., active POZ Personals members) enabled us to reach HIV-positive Black and Hispanic gay men, demonstrating that we can implement a sampling scheme that ensures representation of HIV-positive minority MSM online. Of note, a large number of men clicked on the study email and then immediately exited before consenting. Providing incentives and digital media (e.g., tailored videos) are two approaches that may help to increase the proportion of potential participants. Finally, this study demonstrated our ability to engage 
high-risk HIV-positive men, especially those who use multiple devices and websites or apps to meet sex partners.

This study helped to inform online targeted recruitment techniques, response rates for this recruitment strategy, global sexual risk, access to technology, and social media use on smartphones and tablets among self-identifying HIV-positive gay men from three U.S. states. This study also represented a successful collaboration between a research team and a for-profit institution. The research team made initial contact with POZ, and the relationship developed over several years. During that time, the research team initiated communication regularly, set up meetings regarding mutual research interests, and included $\mathrm{POZ}$ on research proposals.

Translation of existing evidence-based interventions into social media formats and development of new effective interventions that capitalize on technologic media advances are both a priority (Chiasson, Hirshfield, \& Rietmeijer, 2010). Despite evidence that technology-mediated HIV sexual risk reduction approaches are efficacious (Bailey et al., 2012), none have been developed and rigorously tested exclusively for HIV-positive populations, and more specifically, HIV-positive MSM (Pellowski \& Kalichman, 2012). Efficacy trials of technology-based studies to reduce the sexual risk behavior of high-risk HIV-positive MSM are needed. Studies can better engage young MSM in research by utilizing alternate methods for data collection, such as conducting surveys on mobile devices, apps, and by texting. Interventions that can reach and engage high-risk HIV-positive gay men in their daily activities and in a cost-effective manner are advantages of technology-based prevention approaches, and should be further developed.

Acknowledgments We thank Dr. Martin J. Downing, Jr. for his assistance with prior versions of the manuscript, and Smart + Strong for their support with online targeted recruitment. This project was funded by Public Health Solutions.

\section{References}

AAPOR. (2011). Standard definitions: Final dispositions of case codes and outcome rates for surveys [Report]. Retrieved from http://www.aapor. org/AAPORKentico/AAPOR_Main/media/MainSiteFiles/StandardDef initions2011.pdf.

Bailey, J. V., Murray, E., Rait, G., Mercer, C. H., Morris, R. W., Peacock, R., \& Nazareth, I. (2012). Computer-based interventions for sexual health promotion: Systematic review and meta-analyses. International Journal of STD and AIDS, 23, 408-413.

Bolding, G., Davis, M., Sherr, L., Hart, G., \& Elford, J. (2004). Use of gay Internet sites and views about online health promotion among men who have sex with men. AIDS Care, 16, 993-1001.

Catania, J. A., Osmond, D., Neilands, T. B., Canchola, J., Gregorich, S., \& Shiboski, S. (2005). Commentary on Schroder et al.(2003a, 2003b). Annals of Behavioral Medicine, 29, 86-95.

Chiasson, M. A., Hirshfield, S., \& Rietmeijer, C. (2010). HIV prevention and care in the digital age. Journal of Acquired Immune Deficiency Syndromes, 55(Suppl. 2), S94-S97.

Chiasson, M., Parsons, J., Tesoriero, J., Carballo-Dieguez, A., Hirshfield, S., \& Remien, R. (2006). HIV behavioral research online. Journal of Urban Health, 83, 73-85.
Chiasson, M. A., Shaw, F. S., Humberstone, M., Hirshfield, S., \& Hartel, D. (2009). Increased HIV disclosure three months after an online video intervention for men who have sex with men (MSM). AIDS Care, 21, 1081-1089.

Christensen, J. L., Miller, L. C., Appleby, P. R., Corsbie-Massay, C., Godoy, C. G., Marsella, S. C., \& Read, S. J. (2013). Reducing shame in a game that predicts HIV risk reduction for young adult men who have sex with men: A randomized trial delivered nationally over the web. Journal of the International AIDS Society, 16(3 Suppl. 2), 18716.

Cohen, M. S., Chen, Y. Q., McCauley, M., Gamble, T., Hosseinipour, M. C., Kumarasamy, N., et al. (2011). Prevention of HIV-1 infection with early antiretroviral therapy. New England Journal of Medicine, 365, 493505.

Curtis, A. R. (2013). What is social media? [blog post]. Retrieved from http:// www2.uncp.edu/home/acurtis/Courses/ResourcesForCourses/Social MediaWhatIsIt.html.

Fernandez, M. I., Warren, J. C., Varga, L. M., Prado, G., Hernandez, N., \& Bowen, G. S. (2007). Cruising in cyber space: Comparing Internet chat room versus community venues for recruiting Hispanic men who have sex with men to participate in prevention studies. Journal of Ethnicity in Substance Abuse, 6, 143-162.

Gamage, D. G., Sidat, M., Read, T., Cummings, R., Bradshaw, C. S., Howley, K., \& Fairley, C. K. (2011). Evaluation of Health Map: A patientcentred web-based service for supporting HIV-infected patients. Sexual Health, 8, 194-198.

Gorbach, P. M., Drumright, L. N., Daar, E. S., \& Little, S. J. (2006). Transmission behaviors of recently HIV-infected men who have sex with men. Journal of Acquired Immune Deficiency Syndromes, 42, $80-85$.

Gorbach, P. M., Weiss, R. E., Jeffries, R., Javanbakht, M., Drumright, L. N., Daar, E. S., \& Little, S. J. (2011). Behaviors of recently HIV-infected men who have sex with men in the year postdiagnosis: Effects of drug use and partner types. Journal of Acquired Immune Deficiency Syndromes, 56, 176-182.

Grov, C., Breslow, A. S., Newcomb, M. E., Rosenberger, J. G., \& Bauermeister, J. A. (2014). Gay and bisexual men's use of the Internet: Research from the 1990s through 2013. Journal of Sex Research, 51, 390-409.

Grov, C., Golub, S. A., \& Parsons, J. T. (2010). HIV status differences in venues where highly sexually active gay and bisexual men meet sex partners: Results from a pilot study. AIDS Education and Prevention, $22,496-508$.

Grov, C., Ventuneac, A., Rendina, H. J., Jimenez, R. H., \& Parsons, J. T. (2013). Perceived importance of five different health issues for gay and bisexual men: Implications for new directions in health education and prevention. American Journal of Men's Health, 7, 274-284.

Harris, L. T., Lehavot, K., Huh, D., Yard, S., Andrasik, M. P., Dunbar, P. J., \& Simoni, J. M. (2010). Two-way text messaging for health behavior change among human immunodeficiency virus-positive individuals. Telemedicine and e-Health, 16, 1024-1029.

Heijman, T., Geskus, R. B., Davidovich, U., Coutinho, R. A., Prins, M., \& Stolte, I. G. (2012). Less decrease in risk behaviour from pre-HIV to post-HIV seroconversion among MSM in the combination antiretroviral therapy era compared with the pre-combination antiretroviral therapy era. AIDS, 26, 489-495.

Hirshfield, S., Chiasson, M. A., Joseph, H., Scheinmann, R., Johnson, W. D., Remien, R. H., \& Margolis, A. D. (2012). An online randomized controlled trial evaluating HIV prevention digital media interventions for men who have sex with men. PLOS ONE, 7, e46252.

Hooper, S., Rosser, B. R., Horvath, K. J., Oakes, J. M., \& Danilenko, G. (2008). An online needs assessment of a virtual community: What men who use the Internet to seek sex with men want in Internet-based HIV prevention. AIDS and Behavior, 12, 867-875.

Horvath, K. J., Nygaard, K., Danilenko, G. P., Goknur, S., Michael Oakes, J., $\&$ Rosser, B. R. S. (2012). Strategies to retain participants in a long-term 
HIV prevention randomized controlled trial: Lessons from the MINTSII Study. AIDS and Behavior, 16, 469-479.

Horvath, K. J., Oakes, J. M., Rosser, B. R., Danilenko, G., Vezina, H., Amico, K. R., \& Simoni, J. (2013). Feasibility, acceptability and preliminary efficacy of an online peer-to-peer social support ART adherence intervention. AIDS and Behavior, 17, 2031-2044.

Janssen, R. S., \& Valdiserri, R. O. (2004). HIV prevention in the United States: Increasing emphasis on working with those living with HIV. Journal of Acquired Immune Deficiency Syndromes, 37(Suppl. 2), S119-S121.

Kietzmann, J. H., Hermkens, K., McCarthy, I. P., \& Silvestre, B. S. (2011). Social media? Get serious! Understanding the functional building blocks of social media. Business Horizons, 54, 241-251.

Liau, A., Millett, G., \& Marks, G. (2006). Meta-analytic examination of online sex-seeking and sexual risk behavior among men who have sex with men. Sexually Transmitted Diseases, 33, 576-584.

Mustanski, B., Garofalo, R., Herrick, A., \& Donenberg, G. (2007). Psychosocial health problems increase risk for HIV among urban young men who have sex with men: Preliminary evidence of a syndemic in need of attention. Annals of Behavioral Medicine, 34, 37-45.

Mustanski, B., Garofalo, R., Monahan, C., Gratzer, B., \& Andrews, R. (2013). Feasibility, acceptability, and preliminary efficacy of an online HIV prevention program for diverse young men who have sex with men: The keep it up! intervention. AIDS and Behavior, 17, 2999-3012.

Navejas, M., Neaigus, A., Torian, L., \& Murrill, C. (2012). Participation in online and offline HIV prevention among men who have sex with men who use the internet to meet sex partners in New York City. AIDS and Behavior, 16, 389-395.

Pellowski, J. A., \& Kalichman, S. C. (2012). Recent advances (2011-2012) in technology-delivered interventions for people living with HIV. Current HIV/AIDS Reports, 9, 326-334.

Pew Research Center. (2011). Spring tracking survey [Report]. Retrieved from http://pewinternet.org/Trend-Data/Whos-Online.aspx.

Rosser, B. R., Hatfield, L. A., Miner, M. H., Ghiselli, M. E., Lee, B. R., \& Welles, S. L. (2010a). Effects of a behavioral intervention to reduce serodiscordant unsafe sex among HIV positive men who have sex with men: The Positive Connections randomized controlled trial study. Journal of Behavioral Medicine, 33, 147-158.

Rosser, B. R. S., Miner, M. H., Bockting, W. O., Ross, M. W., Konstan, J., Gurak, L., \& Coleman, E. (2009). HIV risk and the internet: Results of the Men's INTernet Sex (MINTS) Study. AIDS and Behavior, 13, 746756.
Rosser, B. R. S., Oakes, J. M., Konstan, J., Hooper, S., Horvath, K. J., Danilenko, G. P., \& Smolenski, D. J.(2010b). Reducing HIV risk behavior of men who have sex with men through persuasive computing: Results of the Men's INTernet Study-II. AIDS, 24, 2099-2107.

Semple, S. J., Patterson, T. L., \& Grant, I. (2000). The sexual negotiation behavior of HIV-positive gay and bisexual men. Journal of Consulting and Clinical Psychology, 68, 934-937.

Singh, S., Bradley, H., Hu, X., Skarbinski, J., Hall,H. I.,Lansky, A., \& Centers for Disease Control and Prevention. (2014). Men living with diagnosed HIV who have sex with men: Progress along the continuum of HIV care-United States, 2010. Morbidity and Mortality Weekly Report, 63, 829-833.

Smith, A. (2010a). Mobile Access 2010 [Report]. Retrieved from http://www. pewinternet.org/Reports/2010/Mobile-Access-2010/Part-2.aspx\#foot note3.

Smith, A. (2010b). Technology trends among people of color [Report]. Retrieved from http://www.pewinternet.org/Commentary/2010/Sep tember/Technology-Trends-Among-People-of-Color.aspx.

Stall, R., \& van Griensven, F. (2005). New directions in research regarding prevention for positive individuals: Questions raised by the Seropositive Urban Men's Intervention Trial. AIDS, 19(Suppl. 1), S123-S127.

Sullivan, P. S., Khosropour, C. M., Luisi, N., Amsden, M., Coggia, T., Wingood, G. M., \& DiClemente, R. J. (2011). Bias in online recruitment and retention of racial and ethnic minority men who have sex with men. Journal of Medical Internet Research, 13, e38.

U.S. Census Bureau. (2012). The Black Alone or in Combination Population in the United States [Report]. Retrieved from http://www.census.gov/ population/race/data/black.html.

Wolitski, R. (2005). The emergence of barebacking among gay men in the United States: A public health perspective. Journal of Gay \& Lesbian Psychotherapy, 9, 13-38.

Wolitski, R. J., Gomez, C. A., \& Parsons, J. T. (2005). Effects of a peer-led behavioral intervention to reduce HIV transmission and promote serostatus disclosure among HIV-seropositive gay and bisexual men. AIDS, 19(Suppl. 1), S99-S109.

Wong, N., Gullo, K., \& Stafford, J. (2004). Gays lead non-gays in cell phone use, cable TV and HDTV viewership. Technology use and preferences of gay and non-gay consumers [News story]. Retrieved from http://www. prnewswire.com/.

Young, S. D. (2013). Social networking technologies as an emerging tool for HIV prevention a cluster randomized trial. Annals of Internal Medicine, 159, 318-324. 